\title{
Analysis of Allocative Efficiency in Northern Pakistan: Estimation, Causes, and Policy Implications
}

\author{
SYED SAJIDIN HUSSAIN
}

\section{INTRODUCTION}

Realising productivity gains in agriculture is an important challenge for Pakistan. With a fast-growing population (3.1 percent per year), it is difficult for the economy to meet domestic food requirements. Like most less developed countries, yields of most crops in Pakistan are lower than the yields realised by researchers in on-farm experiments conducted in the farmers' fields. The average yield gap between the farmers' current yields and what would be profitable and feasible, given existing technology, is reported to be 30 to 40 percent [Byerlee (1987)].

Byerlee (1987), however, suggests that there is a potential for increasing productivity in most of the irrigated areas of Pakistan through the use of new inputs and a more efficient use of the existing inputs to exploit the genetic potential of the existing varieties. He argues that the wide array of new inputs vastly increases the complexity of crop management. ${ }^{1}$ The technical skills required to use the new inputs efficiently are much greater than the simple skills needed to adopt varietal changes. Hence, with more complex technological options and a more dynamic environment, the potential for economic inefficiency (both technical and allocative) is substantially increased.

The purpose of this paper is to measure farm-specific allocative efficiency and the effect of management variables on allocative efficiency of wheat producers in an irrigated area in northern Pakistan. ${ }^{2}$ This will assist researchers, extension agents, and policy-makers to identify the ways and means to increase wheat productivity in Pakistan.

Syed Sajidin Hussain is Agricultural Economist/Technical Adviser (FSR) in the PATA integrated Agricultural Development Project, Saidu Sharif, Swat.

${ }^{1}$ For example, irrigated wheat farmers in Pakistan now commonly purchase five inputs-tubewell water, nitrogenous fertiliser, phosphatic fertiliser, tractor power, and thresher. Other inputs such as herbicides are being introduced to the farmers [Byerlee (1987)].

${ }^{2}$ Analysis of technical inefficiency of wheat farmers in northern Pakistan has been covered in a separate paper [see Hussain (1989)]. The average technical inefficiency of the sample was 31 percent, which is consistent with the technical inefficiency results of most of the studies in the LDCs. 


\section{DATA SOURCES}

The research covers a relatively small homogeneous region in Mardan District, which is one of the important irrigated areas in northern Pakistan. The unit of observation is one of the wheat fields of the selected respondents [see Hussain (1989) for details]. Data were collected from the sample of 105 respondents using a pre-tested questionnaire. Information was obtained from the sample farmers in four visits during the wheat season (December 1987 to June 1988), emphasising farmers' resource base, inputs and management practices in wheat, and their yields. In addition, visits were made to the sample wheat fields to obtain soil samples, and to observe the weeds and disease infestation.

\section{THEORETICAL DISCUSSION}

\section{Model of Allocative Efficiency}

The interpretation of allocative efficiency, or in a broader sense, economic efficiency, depends on the assumptions we make about the farmers' behaviour. Farrell (1957) assumed cost minimisation for a given level of output and defined allocative inefficiency as the inability of the farmers to equate the ratio of marginal products of inputs with the ratio of their prices. Lau and Yotopolous (1971); Schmidt and Lovell (1979), Kopp and Diewert (1982), and Zieschang (1983) assumed alternative approaches of profitmaximising behaviour of farmers and defined allocative inefficiency as the failure to equate the marginal value product (MVP) of inputs to their prices.

Byerlee (1987) has suggested that it is often useful for policy purposes to subdivide allocative efficiency between (a) the constrained case, where allocative gains are measured by reallocating inputs within a constant cost level, and (b) the unconstrained case, where allocative gains are achieved due to movement along the expansion path until the marginal return on expenditure is equal to the cost of capital. He argues that allocative inefficiency in the constrained case is likely to reflect deficiencies in information and skills. Allocative inefficiency in the unconstrained case (i.e., scale inefficiency) may also reflect inadequate information and skills, but it may also arise due to market imperfections, cash constraints, risk aversion, and non-monetary goals of farmers that may require long-run interventions.

In this study, constrained allocative inefficiency of the farmers is considered because it has more policy relevance in the short run. It is assumed that an individual small farmer has a fixed land, labour, and cash outlay which he allocates among the various crops produced during the season. His overall objective might be to maximise profits at the time he is making this decision. However, once he allocates a piece of land and an associated cash outlay to a particular crop, his objective is to maximise output, given the cash outlay allocated for that crop. 
Let the estimated production frontier from a cross-sectional sample be,

$$
\begin{array}{llllll}
y=f(x, b) & \ldots & \ldots & \ldots & \ldots & \ldots
\end{array}
$$

where $f$ relates the frontier output $y$ of individual farmer to the vector of inputs $x$, and $b$ is the estimated vector of coefficients. Assume the farmer desires to obtain the greatest possible output for a given cost outlay $\left(c^{\circ}\right)$. Mathematically, his problem can be expressed as:

Maximise

$$
f(x, b)
$$

Subject to

$$
c^{0}=\sum_{j=1}^{m} r_{j} x_{j} \quad \cdots \quad \ldots \quad \ldots \quad \ldots \quad \ldots
$$

where $f($.$) represents Equation (1), r_{j}$ is the price of the $j$ th input $\left(x_{j}\right)$ and $m$ denotes the number of inputs purchased. ${ }^{3}$ The cost-constrained maximum output $\left(y^{*}\right)$ of the farmer is obtained by substituting the cost-constrained output maximising input levels $\left(x^{*}, \ldots, X^{*}\right)$ directly in production frontier (1) i.e.,

$$
y^{*}=\left(r_{1}, \ldots \ldots, r_{m}, c^{0}\right) \quad \ldots \quad \ldots \quad \ldots \quad \ldots \quad \ldots
$$

Note that $y^{*}$ pertains to the optimum output levels of the individual farmer for a given level of prices and cost outlay. This optimum output level will vary across farmers because the cost outlay varies across farmers.

To obtain $y^{*}$ for each observation, the systems of first-order equations of problem (1) must be solved simultaneously. Numerical optimisation with a Quasi Newton method was used to solve this problem.

\section{EMPIRICAL MODEL FOR FRONTIER PRODUCTION FUNCTION}

The stochastic frontier production model of Aigner et al. (1977) and Meeusen and Van den Broeck (1977) has been used. The empirical model is the restricted translog frontier production function represented as follows. ${ }^{4}$

$$
\begin{aligned}
& \ln \text { WHTOUTPUT }=\beta_{0}+\beta_{1} \ln \text { TILLAGE }+\beta_{2} \ln L A B O U R+\beta_{3} \ln \text { SEED } \\
& +\beta_{4} \ln \text { FERTILISER }+\beta_{5} \ln \text { HERBICIDE }+\beta_{6} \ln \text { PLOTSIZE } \\
& +\beta_{11}(\ln \text { TILLAGE })^{2}+\beta_{12} \ln \text { TILLAGE* } \ln \text { LABOUR } \\
& +\beta_{22}(\ln L A B O U R)^{2}+\beta_{33}(\ln S E E D)^{2}+\beta_{44}(\ln \text { FERTILISER })^{2} \\
& +\beta_{45} \ln \text { FERTILISER* }{ }^{*} \ln \text { HERBICIDE }+\beta_{55}(\ln \text { HERBICIDE })^{2} \\
& +\beta_{66}(\ln \text { PLOTSIZE })^{2}+v-u \quad \ldots \quad \ldots \quad \ldots \quad \ldots
\end{aligned}
$$

${ }^{4}$ This model was selected after various statistical tests for specification of functional forms [see Hussain (1989)]. The model is called restricted because some of the interaction terms in the production frontier were restricted to zero. 
where $\ln$ denotes the natural logarithm of the variables and $\beta$ 's are the parameters to be estimated. The term $v$ is symmetric, distributed normally and independently, and captures the stochastic effects outside the farmers' control such as weather, etc. The term $u$ is one-sided error, distributed as half normal, and captures the technical inefficiency of the farmer. WHTOUTPUT is the dependent variable defined as wheat-grain output produced from the specific plot. The independent variables are: (1) TILLAGE: measured as the total number of ploughings (using animals and/or tractor) given to the plot for seed-bed preparation and planting; (2) LABOUR: measured as person-hours utilised for wheat production per plot; (3) SEED: measured in kg. per plot used for wheat planting; (4) FERTILISER: measured in kg. of nitrogen and/or phosphorus nutrients applied to the wheat plot; (5) HERBICIDE: measured as kg. of 2,4-D applied to the wheat plot for killing broadleaf weeds; ${ }^{5}$ (6) PLOTSIZE: defined as size of the selected plot measured by the researchers in hectares.

\section{RESULTS AND DISCUSSION}

The Maximum Likelihood Estimates (MLE) of the restricted translog frontier production model (4) are presented in Column 1 of Table $1 .^{6}$ The coefficients for the $\ln$ of fertiliser as well as the square of the $l n$ of fertiliser are highly significant (1 percent probability level) and show the expected quadratic response. The $\ln$ of plot size is also significant at 5 percent and has a quadratic response. The coefficient for the $\ln$ of labour is significant at 10 percent probability level but shows a declining marginal productivity. The coefficients for $\ln$ of seed and $\ln$ of herbicide are negative but not significant. As expected, the interactions between $\ln$ of tillage and $\ln$ of labour, and between $\ln$ of fertiliser and $\ln$ of herbicide, are positive but not significant.

\section{Estimates of Allocative Efficiency}

The allocative efficiency for each farmer was computed in two steps. In the first step, the cost-constrained maximum output $f$ or each farmer was derived, given the production frontier, input prices, and cost outlay. In the second step, the ratio of predicted output to the cost-constrained maximum output was computed.

Cost-constrained maximum output levels of farmers were obtained by solving the first-order equations of problem (1) simultaneously, where $f($.$) is the estimated restricted$ translog production frontier model (4) and $c^{0}$ is the sum of input costs (seed, labour, tillage, fertiliser, and herbicide) for each individual farmer using the 1987 farm-gate prices. Constrained-output maximising input allocations were derived initially by

${ }^{5}$ The herbicide variable is assigned a zero value for non-users of herbicide. To avoid $\ln (0)$ we added 0.1 to each value.

${ }^{6}$ Ordinary Least Squares (OLS) results of the model are also shown in Table 1 for comparison. Most of the coefficients of the OLS estimates were significant at 10 percent or lower probability levels. However, some of the OLS coefficients which were significant are not significant in the frontier model. 
Table 1

Maximum Likelihood Estimates of Frontier Production Models Dependent Variable $=$ In of Wheat Output in Metric Tons

Number of Observations $=105$

\begin{tabular}{|c|c|c|}
\hline \multirow[b]{2}{*}{ Independent Variable } & \multicolumn{2}{|c|}{ Coefficient } \\
\hline & MLE & OLS \\
\hline \multirow[t]{2}{*}{ CONSTANT } & -0.578 & -0.199 \\
\hline & $(-0.266)^{1}$ & $(-0.131)$ \\
\hline \multirow[t]{2}{*}{ ln TILLAGE } & -0.126 & -0.217 \\
\hline & $(-0.127)$ & $(-0.251)$ \\
\hline \multirow[t]{2}{*}{ In LABOUR } & $-0.860 * * *$ & $-0.929 *$ \\
\hline & $(-1.713)$ & $(-2.498)$ \\
\hline \multirow[t]{2}{*}{ ln SEED } & -1.042 & $-1.371^{* *}$ \\
\hline & $(-1.348)$ & $(-2.351)$ \\
\hline \multirow[t]{2}{*}{ In FERTILISER } & $1.834^{*}$ & $1.771^{*}$ \\
\hline & (3.356) & $(4.045)$ \\
\hline \multirow[t]{2}{*}{ ln HERBICIDE } & -1.278 & $-1.145 * * *$ \\
\hline & $(-1.349)$ & $(1.833)$ \\
\hline \multirow[t]{2}{*}{ In PLOT-SIZE } & $0.623^{* *}$ & 0.434 \\
\hline & $(2.05)$ & $(1.321)$ \\
\hline \multirow[t]{2}{*}{$(\ln \text { TILLAGE) })^{2}$} & -0.448 & -0.487 \\
\hline & $(-1.016)$ & $(-1.228)$ \\
\hline \multirow[t]{2}{*}{ ln TILLAGE* $\ln$ LABOUR } & 0.368 & $0.419^{* *}$ \\
\hline & $(1.443)$ & $(2.075)$ \\
\hline \multirow[t]{2}{*}{$(\ln \mathrm{LABOUR})^{2}$} & 0.082 & $0.851^{*}$ \\
\hline & $(1.097)$ & $(2.76)$ \\
\hline \multirow[t]{2}{*}{$(\ln \mathrm{SEED})^{2}$} & $0.198^{* * *}$ & $0.255^{*}$ \\
\hline & $(1.678)$ & $(2.76)$ \\
\hline \multirow[t]{2}{*}{$\ln (\text { FERTILISER) })^{2}$} & $-0.203 *$ & $-0.204^{*}$ \\
\hline & $(-3.657)$ & $(-4.138)$ \\
\hline ln FERTILISER* & 0.250 & $0.208^{* * *}$ \\
\hline ln HERBICIDE & $(1.312)$ & $(1.674)$ \\
\hline \multirow[t]{2}{*}{$(\ln \text { HERBICIDE) })^{2}$} & $-0.161^{* * *}$ & $-0.169 * *$ \\
\hline & $(-1.636)$ & $(-2.308)$ \\
\hline \multirow[t]{2}{*}{$(\ln \text { PLOT-SIZE) })^{2}$} & -0.060 & -0.106 \\
\hline & $(-0.742)$ & $(-1.152)$ \\
\hline \multirow[t]{2}{*}{ LAMBDA(I) } & $2.687^{* *}$ & - \\
\hline & $(2.415)$ & \\
\hline \multirow[t]{2}{*}{ Standard Error $\left(\sigma_{\mathrm{e}}\right)$} & $0.417^{*}$ & $0.417 *$ \\
\hline & (8.199) & (8.199) \\
\hline Adjusted $R^{2}$ & 0.830 & 0.830 \\
\hline Ln-likelihood & -10.498 & - \\
\hline
\end{tabular}

${ }^{1}$ Figures in parenthesis are $t$-values.

$*, * *, * * *$, significant at 1 percent, 5 percent, and 10 percent level, respectively. 
allowing all the inputs in the production frontier to vary except the plot-size. Plot-size was assumed fixed at the observed level because it can not be changed during the production process.

The labour-seed allocations of the individual farmers produced by the output maximisation problem were significantly different than the observed allocations and were not realistic. This probably occurred because the output maximisation solution extrapolated the estimated production function to regions outside of observed input allocations. This can cause problems because the estimated translog function is valid only as local approximation [see, for example, Caves and Christensen (1980)].

To avoid this problem, labour and seed inputs were fixed at the observed level. ${ }^{7}$ Cost outlay was then computed for the three cash inputs-tillage, fertiliser, and herbicide - and their constrained-output maximising input allocations $\left(x^{*}\right)$ were derived. Cost-constrained maximum output levels $\left(y^{*}\right)$ for the individual farmers were obtained by substituting the output-maximising input allocations for tillage, fertiliser, and herbicide directly into the estimated translog production frontier (model 4).

Allocative efficiency for each individual farmer was obtained by computing the ratio of predicted output $\left(y^{p}\right)$ from the estimated production frontier to the cost constrained maximum output $\left(\mathrm{y}^{*}\right)$. The mean allocative efficiency of the sample farmers is 42.5 percent and ranges from 8 percent to 70 percent. Most of the farmers are centred around the mean allocative efficiency. Unlike previous studies in LDCs, these results suggest that allocative inefficiency of the farmers is relatively more important than technical inefficiency.

As a check on whether the constrained-output maximising solution satisfies the marginal conditions for profit maximisation, we computed the following relationship;

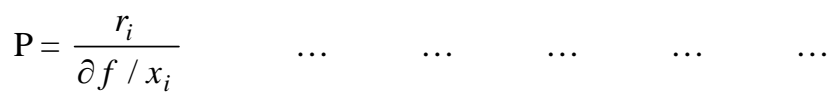

where $P$ is the output price, $\partial f / x_{i}$ is the marginal product of input $i$ and $r_{i}$ is the price of input $i$. Relationship (5) states that the output price should be equal to the marginal cost of each input in order to satisfy the profit-maximising marginal conditions [Forsund et al. (1980) defined these conditions for scale efficiency].

Note that at the constrained-output maximising solution, the marginal costs of all inputs (tillage, fertiliser, and herbicide) are equal to one another. Thus, at optimum input levels, if Equation (5) is satisfied by one input, then it is also satisfied by the other inputs. When the constrained-optimum solution is formed for the sample farmers, the marginal cost of an input for the average farmer is Rs 438/ton, which is fairly low as compared to

${ }^{7}$ It is reasonable to treat labour as a fixed variable because all labour is family labour which is unlikely to be varied during a single production period. The reason for treating seed as a fixed input was that farmers tend to use only one seeding rate irrespective of prices observed. This is mainly because farmers use seed retained from previous harvests. 
the prevailing output price of Rs 2100/ton. The minimum marginal cost observed in the sample is Rs 22/ton and the maximum marginal cost is Rs 4000/ton. The value of $K$ (ratio of output price to marginal cost) is 9.7 for the sample average and ranges from 0.5 to 94. Most of the farmers have value of $K$ greater than 1.25 . $^{8}$

The question as to which of the variable inputs (tillage, fertiliser, and herbicide) are the farmers using too much or too little of was analysed by computing the percentage deviation of actual input levels from the cost-constrained output maximising input levels. Most of the farmers (64 percent) are allocatively efficient in the use of herbicide for weed control and quite a few (20 percent) are also allocatively efficient in the use of fertiliser, given the cost outlay. However, most of the farmers (67 percent) are using fertiliser lower than the optimum dose required to obtain maximum output, given the cost outlay [see Hussain (1989) for detail].

The variable contributing most to lower allocative efficiency is the tillage input. Almost all the farmers are using many more ploughings ( $>100$ percent) required to obtain the maximum amount of wheat output. This result suggests that farmers need to re-allocate their cash resources by using more fertiliser and less ploughings to obtain maximum wheat output. This result, however, must be read with caution, especially for tillage input for the following reasons: (a) The use of the translog production function for estimating allocative efficiency is valid only as local approximation and might not perform well if the estimated input allocations are observed outside the range of observed input allocations. The optimal allocation for herbicide is well within the observed range and the optimal allocation for fertiliser is, at least, close to the actual level. The optimal allocation for tillage input is far below the observed range. Thus the translog model might not be performing well in extrapolating the tillage input. The low allocative efficiency might also be because the true production function has a plateau which the translog model fails to pick up. This would cause the cost-constrained output maximum to be larger than is actually feasible. (b) Farmers are in fact using more ploughings than required for tillage operation to obtain maximum wheat output. This possibility arises because when sugarcane is intercropped with wheat, better seed-bed preparation is required than if wheat is planted alone. Thus the estimates of allocative efficiency by considering wheat crop alone might not be valid if the farmers' decisions on input use depend on multiple crops. (c) Farmers may not be facing the prices we assumed when computing allocative efficiency. This may be particularly true for the tillage price. Farmers used rented tractors and/or own animals for ploughings. Since no market price prevailed for hiring animals for ploughings, we assumed tractor rental fees as the opportunity cost of using own animals for ploughings. If the true cost of animals

${ }^{8}$ Risk-aversion due to price uncertainty may be one reason that the marginal cost is lower than the market price of output. We have not incorporated a risk premium in the marginal cost of inputs. The significance of this factor is questionable because both input and output prices have been fairly stable in the area since the early 1980 s. 
for ploughings is lower than what we assumed (which it most probably is), then the measure of allocative efficiency will be downward biased.

\section{Results on Causes of Allocative Efficiency}

The major sources of allocative inefficiency discussed in the recent literature are the management qualities of farmers, e.g., formal education, extension contacts, experience, and some index of knowledge. It has been argued that management qualities, especially formal education, have a production value because they both enable farmers to increase productivity, and also because they help farmers to allocate their resources in a cost-efficient manner. Education may enhance both technical efficiency and allocative efficiency [Jamison and Moock (1984); Welch (1970)] labels these as 'the worker and allocative effects of education'. The former (the worker effect) is related to the enhanced ability of production with a given set of inputs, and the latter (allocative effect) has to do with farmers' ability to process information about costs, etc. [Cotlear (1986)].

In this section, an attempt is made to determine whether the management characteristics (age, education, extension contacts, and knowledge score) have an impact on the cost-constrained output maximising allocative efficiency of the farmers or not. These were analysed by assuming a linear relationship between allocative efficiency and explanatory variables. The explanatory variables were the set of management variables, e.g.: (a) AGE: age of the respondent (number of years). We use this variable as a proxy for management experience in farming, (b) EDUCATION: Education of the farmer, defined as number of years of formal schooling. (c) EXTENSION: Dummy variable defined as 1 if the farmer or any other member of his family has visited an extension office during the previous two years and 0 otherwise. (d) KNOWLEDGE: Knowledge score of the respondent about agricultural technology. This variable deals mainly with the computational ability of the farmer (e.g., the ability to compute fertiliser doses, the carry-over effects, etc.). Education variables were also used in the form of two dummies: EDUCATION1 to reflect primary education or higher, and EDUCATION2 to reflect secondary education or higher. Farm size (FARMSIZE) was included as a proxy for cash availability (i.e., large farmers have more cash resources than small farmers). The two other variables included in the regression were: (a) DANIMAL: defined as the animal power as percentage of total power (tractor + animals) used for tillage. We included this variable to capture the price differences, if any, for the use of tractor and animals. (b) DVILLAGE: dummy variable defined as 1 if the sample villages were close (1 km or less) to the main marketing centre, and 0 otherwise.

The OLS regression results explaining allocative efficiency are shown in Table 2. The results show that the only variable which significantly affected allocative efficiency of the farmers in Mardan District was the village dummy (DVILLAGE) representing the distance of the village from the marketing centre. Farms which are close to the 
marketing centres have a relatively higher allocative efficiency (11 percent) than farms which are further away from the marketing centres, probably because of easier interaction with marketing agents (e.g., shopkeepers, gur mundies, banks, etc.).

Table 2

\begin{tabular}{|c|c|c|}
\hline \multirow[b]{2}{*}{ Independent Variable } & \multicolumn{2}{|c|}{ OLS Coefficient } \\
\hline & Regression 1 & Regression 2 \\
\hline \multirow[t]{2}{*}{ CONSTANT } & $0.335 *$ & $0.358 *$ \\
\hline & $(4.581)^{1}$ & $(5.213)$ \\
\hline \multirow[t]{2}{*}{ DVILLAGE } & $0.110^{*}$ & $0.110^{*}$ \\
\hline & (2.579) & $(2.631)$ \\
\hline \multirow[t]{2}{*}{ FARMSIZE } & 0.003 & - \\
\hline & $(0.895)$ & \\
\hline \multirow[t]{2}{*}{ DANIMAL } & 0.001 & - \\
\hline & $(0.042)$ & \\
\hline \multirow[t]{2}{*}{ AGE } & 0.001 & 0.001 \\
\hline & $(0.83)$ & $(0.631)$ \\
\hline \multirow[t]{2}{*}{ EDUCATION } & 0.002 & - \\
\hline & $(0.736)$ & \\
\hline \multirow[t]{2}{*}{ EDUCATION 1} & - & -0.028 \\
\hline & $(0.890))$ & \\
\hline \multirow[t]{2}{*}{ DEDUCATION2 } & - & -0.028 \\
\hline & $(-0.707)$ & \\
\hline \multirow[t]{2}{*}{ EXTENSION } & -0.008 & -0.0089 \\
\hline & $(-0.242)$ & $(-0.121)$ \\
\hline \multirow[t]{2}{*}{ KNSCORE } & 0.003 & 0.010 \\
\hline & $(0.326)$ & $(0.431)$ \\
\hline \multirow[t]{2}{*}{ Sigma } & $0.127 *$ & $0.126^{*}$ \\
\hline & (14.491) & (14.491) \\
\hline Adjusted $R^{2}$ & 0.030 & 0.036 \\
\hline
\end{tabular}

${ }^{1}$ Figures in parenthesis are $t$-values.

*Significant at 1 percent level.

The effect of the rest of the variables on allocative efficiency was positive except for extension contacts. However, the coefficients for all of these variables were small as well as insignificant. 
Thus, not much is explained by regressions determining the causes of allocative efficiency. The adjusted $R^{2}$ s for these regressions is only 3 percent. One reason for such a low $R^{2}$ is the small variation in the estimates of allocative efficiency itself. The coefficient of variation for the estimates of allocative efficiency in the sample was only 0.3 percent. The second reason for the poor results might be the measurement problem as discussed in the previous section. For example, the use of the translog model for estimating allocative efficiency can provide misleading results in cases in which extrapolation of inputs is involved. This was especially observed for tillage input: the optimal solution for tillage input was far below the actual level used by the farmers. Errors in the measurement of input prices (particularly the tillage price) might be another reason for the poor results. If the true cost of animals for ploughings is lower than the tractor rental fees, the measure of allocative efficiency will be downward biased. However, in the regression of causes of allocative efficiency, the variable explaining animal power as a percentage of the total power used for tillage was positive but insignificant.

Measurement problem might also be due to misinterpretation of the farmer's objectives. For example, rather than simply maximising output (wheat-grain) from the plot, farmers might be interested in maximising food for family, feed for animals, and cash for purchasing inputs and other family consumption items. One can also argue that farmers make allocative decisions based on the whole crop rotation in the plot over time, rather than making decisions based on a single crop in a particular season. This makes more sense in an area where farmers are able to produce more than one crop in a year [Byerlee et al. (1986)]. For example, the effect of crop rotations on farmer's management decisions in Mardan District can be classified into (i) time conflicts in the harvesting of preceding crops (e. g., sugarcane and/or maize) and the planting of wheat, and (ii) carry-over crop rotation effects, particularly soil nutrient carry-over and weed population effects [Hussain, Ahmad, and Longmire (1992)]. Both time conflicts and carry-over effects of crop rotations have implications not only for allocative decisions but also for overall wheat productivity. This would seem to be an important aspect of future research.

Finally, poor regression results explaining causes of allocative efficiency might be due to the fact that there are some other factors affecting allocative efficiency that have not been included in the analysis: perhaps there are external factors/constraints other than farmer's management characteristics. One of the variables in the regression, the distance of the farm from the marketing centre (DVILLAGE) confirms the fact that external factors are important determinants of allocative efficiency. The variable was significantly positive as well as large. Other external factors potentially affecting allocative efficiency include risk and uncertainty due to market imperfections, lack of information about input prices, supply of inputs, and cash constraints. We have not been 
able to include these external factors in the regression due to lack of data on these variables. Future studies might consider these external factors explaining the causes of allocative efficiency.

\section{SUMMARY AND CONCLUSION}

The sample allocative efficiency was only 42.5 percent, which implied that substantial potential exists in the area to maximise the wheat output (or reduce costs) by re-allocating the use of inputs within existing cash expenditure. The results also imply that allocative inefficiency is as important as technical inefficiency in irrigated Northern Pakistan. These results, however, do not confirm the previous studies in LDCs wherein higher allocative efficiency of the farmers has been observed as compared to the technical efficiency. The estimates of allocative efficiency were also relatively lower than of the other studies in LDCs.

To increase allocative efficiency, farmers need to re-allocate their cash resources by increasing the use of fertiliser and reducing the number of ploughings for tillage operation. It was, however, suggested that the estimates of allocative efficiency must be read with caution due to possible measurement problems and misinterpretation of farmers' objectives.

Not much was explained by the regressions on the causes of allocative efficiency. None of the management variables explained the allocative efficiency of the farmers. Access of the farmers to the marketing centres was the major source of allocative efficiency, implying that external factors (interaction of the farmers with the marketing agents) play an important role in achieving higher allocative efficiency.

\section{REFERENCES}

Aigner, D. J., C. Lovell, and P. Schmidt (1977) Formulation and Estimation of Stochastic Frontier Production Function Models. Journal of Econometrics 6: 21-38.

Byerlee, D. (1987) Maintaining the Momentum in Post-Green Revolution Agriculture: A Micro-level Perspective from Asia. MSU International Development Paper No. 10. University of Michigan.

Byerlee, D., P. Hobbs, and A. D. Shiekh (1986) Increasing Wheat Productivity in Pakistan's Irrigated Cropping Systems: A View from the Farmers' Field. Islamabad: Pakistan Agricultural Council. (Research Report PARC/CIMMYT.)

Caves, D., and L. Christensen (1980) Global Properties of the Flexible Functional Form. American Economic Review 70: 422-432.

Cotlear, D. (1986) Farmer Education and Farm Efficiency in Peru: The Role of Schooling, Extension Services and Migration. Education and Training Department, World Bank: Education and Training Department. (Discussion Paper No. EDT49.) 
Farrell, M. J. (1957) The Measurement of Productive Efficiency. Journal of Royal Statistics Society. Series A. 120: 253-281.

Forsund, F. R., C. A. K. Lovell, and P. Schmidt (1980) A Survey of Frontier Production Functions and their Relationship to Efficiency Measurement. Journal of Econometrics 13:1 5-25.

Hussain, S. S. (1989) Analysis of Economic Efficiency in Northern Pakistan: Estimation, Causes and Policy Implications. Unpublished Ph.D Thesis. UrbanaChampaign: University of Illinois.

Hussain, S. S., M. Ahmad, and J. Longmire (1992) Multi-enterprise Systems of the Irrigated Peshawar Valley: Subsistence and Cash Cropping. Chapter 7. In Derek Byerlee and Tariq Husain (eds) Farming Systems of Pakistan; Diagnosing Priorities for Agricultural Research.

Jamison, D. T., and P. R. Moock (1984) Farmer Education and Farm Efficiency in Nepal: The Role of Schooling, Extension Services and Cognitive Skills. World Development 12: 67-86.

Kopp, R. J., and W. E. Diewert (1982) The Decomposition of Frontier and Cost Function Deviations into Measure of Technical and Allocative Efficiency. Journal of Econometrics 19: 319-331.

Lau, L. J., and P. A. Yotopoulos (1971) A Test for Relative Efficiency and an Application to Indian Agriculture. American Economic Review 61:1 97-109.

Meeusen, W., and Van den Broeck (1977) Efficiency Estimation from Cobb-Douglas Production Function with Composed Error. International Economic Review 18:2 435-444.

Schmidt, P., and C. A. K. Lovell (1979) Estimating Technical and Allocative Inefficiency Relative to Stochastic Production and Cost Frontiers. Journal of Econometrics 9:3 343-366.

Welch, F. (1970) Education in Production. Journal of Political Economy 78: 35-39.

Zieschang, K. D. (1983) A Note on the Decomposition of Cost Efficiency into Technical and Allocative Components. Journal of Econometrics 23: 401-405. 